by J. Deyo, J. Toma, and R. B. King Lewis Research Center

Cleveland, Ohio 44135

TECHNICAL PAPER to be presented at Sixty-eighth Annual Meeting of the Air Pollution Control Association Boston, Massachusetts, June 15-20, 1975

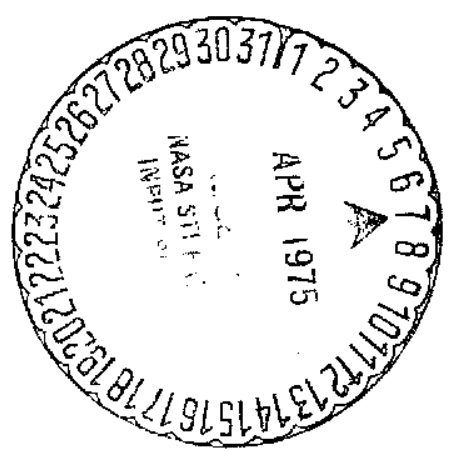




\title{
DEVELOPMENT AND TESTING OF A PORTABLE WIND SENSITIVE DIRECTIONAL AIR SAMPLER
}

\author{
by J. Deyo, J. Toma, and R. B. King \\ Lewis Research Center \\ National Aeronautics and Space Adninistration \\ Cleveland, Ohio
}

\section{Abstract}

A portable wind sensitive directional air sampler has been developed as part of an alr pollution source identification system. The system is designed to identify sources of air pollution based on the directional collection of field air samples and their analysis for TSP and trace element characteristics. Sources can be identified by analyzing the data on the basis of pattern recognition concepts.

The function of the equipment described is to collect air samples in the field automatically with respect to wind direction and at controllable frequencles.

A prototype portable sampler has been designed, fabricated and subjected to initial testing. The unit, designated Air Scout, recelves wind direction signals from an associated wind vane. Air samples are collected on filter slides using a standard high volume air sampler (hi vol) drawing air through a porting arrangement which tracks the wind direction and permits collection of discrete samples. A preset timer controls the length of time each filter is in the sampling position. At the conclusion of the sampling period a new filter is automatically moved into sampling position displacing the previous filter to a storage compartment. Thus the Air Scout may be set up at a field location, loaded with up to 12 filter slides, and left to acquire air samples automatically, according to the wind, at any timer interval desired from 1 to 30 hours.

Testing of the prototype Atr Scout involves a functional and reliability evaluation of the unit as well as field testing to assess its performance in resolving sources as well as determining limits of sampling times and flow rates required.

Functional testing has confirmed the suitability of all of the components and subsystems. The field evaluation has been initiated and is concentrating initially on comparing particulate samples collected by the Air scout and standard hi vols without regard to wind direction. Tests will be conducted in both clean and dirty atmospheric environments. Following these tests directional resolution of sources will be evaluated first with a single isolated source and then with multiple sources.

Completion of the field tests now in progress will provide the information necessary to more fully assess the potential of the Air Scout concept as a source identification tool. 


\section{DEVELOPMENT AND TESTING OF A PORTABLE WIND SENSITIVE DIRECTIONAL AIR SAMPLER}

\section{Introduction}

From 1971 through 1973 the City of Cleveland Diviston of Alr Pollution Control and the NASA Lewis Research Center (LeRC) carried on a two-fold cooperative program. Goals were to assess the levels of trace elements and compounds In the ambient air and to develop techniques, using trace element and compound data in conjunction with meteorological information, to identify specific polluting sources. Sampling stations were chosen from an existing Cleveland air monitoring network to provide a west to east range of environments from typicalurban residential to heavy central industrial and back to urban residential. The variation in wind direction provides a wide range of environments. The intent in the second objective was to develop a practical system that could be readily utilized by an enforcement or control agency.

During the analysis of the trace element and compound data to seek relationships among the materlals identified and the environment of the collection site ${ }^{1}$, a method of displaying the data as concentration roses was developed. In this procedure the 24 -hour average concentration levels at each monitoring site were separated into one of sixteen groups according to the resultant wind direction for that day ${ }^{2}$. This resulted in a computer print-out for each element and compound for each of the sixteen monitoring sites, Figure 1.

Although the utility of this procedure as an indicator for seeking local emission sources is obvious, it is not yet specific enough for positive identification using the particular ratios of elements or "source signatures" associated with a specific industrial or manufacturing process or combination of processes. This is due to the lack of directional specificity inherent in the 24-hour averaged resultant direction. The need for data that truly reflects the wind direction became evident and led to the concept of a wind-direction, time-resolving air sampler. Separating the particulate matter according to wind direction over shorter averaging time periods is the necessary first step in this source identification system. The sampler designated Air Scout to be described subsequently separates the particulate matter into eight groups corresponding to eight wind directions. Analysis of this material provides elemental ratios of the emisstons from sources in that direction. Comparison with those found to be associated with various types of sources permits the unambiguous identification of the sources in question. Identification will be implemented with computer programs using pattern recognition techniques 3,4 . In addition, concentration roses will be regularly produced and placed in their geographical positions so.that site interrelationships can be evaluated. The Air Scout provides directional samples to be used for trace element purposes and TSP values averaged over the time period chosen by the operator.

The design of the Air Scout also permits its use as an unattended total suspended particulate (TSP) sampler capable of collecting samples over long or short time periods. It is equally suitable in this respect for collecting samples over short averaging times in cases where sources are suspected of emissions under cover of darkness, etc.; or for longer periods of time such as eight hour sampling times common during an air pollution episode.

Others have recognized the need for time resolved sampling. Rahn and co- 
workers ${ }^{5}$ developed an automated filter changer. Cah $111^{6}$ ut $111 z e s$ a modified Lundgren sampler in a State of California network. For sampling according to wind direction, Duce and coworkers ${ }^{7}$ devised a system for shipboard application. Air Scout represents the first attempt to combine these two sampling variables.

\section{Air Scout Description}

The need for a time and wind direction resolving air sampler, which would be suitable for use by an enforcement agency, required the consideration and establishment of a number of design and operational groundrules. Major groundrules adopted were as follows:

1. Directional resolution: $45^{\circ}$ minimum, or $\pm 22 \frac{1}{2}^{\circ}$ from each of the major compass headings of $\mathrm{N}, \mathrm{NE}, \mathrm{E}, \mathrm{SE}, \mathrm{S}, \mathrm{SW}, \mathrm{W}$, and $\mathrm{NW}$.

2. Single sample time range: one to thirty hours.

3. Sampler automatic operation schedule: up to seven days either continuous or intermittent.

4. Power requirements: $115 \mathrm{~V}-60 \mathrm{~Hz}$ : 15 to 20 amperes maximum.

5. Sample collection technique: high volume (hi vol) air sampling motor assembly. Whatman-41 filters ${ }^{8}$ for directional samples. Glass fiber filters for TSP samples.

6. Portability: minimize weight. Wheels for manual ground movement.

7. Wind sensors: wind speed and wind direction with electrical signals to Air scout for control and recording.

8. Cost: commercial components where suitable and simplified construction to minimize cost.

9. Field installation and operation: setup and operation possible without tools or extensive training. Minimum handling of sample filters before and after exposure.

From these nine groundrules, a design was developed. Functionally the chassis is divided into a storage section for unexposed filter slides, a directional air sampling section, and a storage section for exposed filter slides. The loose fitting cover permits air to enter freely around the skirt for sampling while excluding rain, snow, and wind-born dirt and dust. Wind information is supplied by electrical signals from wind speed and direction sensors mounted on a tower located in an unobstructed position at the site. Major areas of the design included the controls, hi vol porting valves, filter slides and change mechanism, wind sensing system, and chassis.

Two modes of control are provided on the Air Scout. An automatic mode controls all functions during normal unattended sampling operations. In this mode, with the wind sensors connected, power supplied to the unit, and timers set for the desired slide change period and machine operation sequence, the Air Scout will collect up to 12 filter slides of particulate samples automatically according to wind direction without further attention. A manual mode permits the operator to test: (1) the slide transfer mechanism, (2) the hi vol directional porting valves, and (3) operation and flow calibration of the hi vol. A variable transformer is provided for setting the hi vol flow rate by varying hi vol motor speed. A circular chart recorder and pressure transducer monitors and records the total hi vol discharge air pressure with respect to ambient air pressure. The slide changing mechanism, hi vol directional valves, and wind sensors are connected to the control system through 
standard industrial relays having conservative ratings to Insure long life.

Eight individual electrically actuated poppet valves, positioned in a circular pattern in a housing above the hi vol, control air flow through the ports (see Figures 2 and 3 ). Each port represents one of the eight directions of the compass noted. A solenoid actuates each valve and is connected electrically to a set of contacts in the wind vane corresponding to the direction assigned to the valve. Thus each valve, when open, permits collecting a particulate sample in a discrete location on a fllter slide when it is in sampling position over the housing. The sample thus collected represents particulates In the air coming from a $45^{\circ}$ arc of the compass. The central hole in the housing does not have a control valve. It is open continuously so that the sample collected on the filter slide can provide a measure of the TSP. Advantages of this valve configuration include: elimination of valve stem seals, reduction of valve wear due to airborne particulates by the upstream position of the air filter, cooling of the valve solenoid by the air passing through the valve, and simplified valve servicing because of single attachment to the removeable top surface of the housing. The solenoids opening the valves have sufficient force to overcome the suction of the hi vol which runs continuously during valve and filter slide changing. Response time of the valves is significantly faster than wind direction changes under gusty conditions so that no lag is experienced.

The fllter slide assembly consists of a stainless steel pan, the filter elements, and a sealing cover. The pan is fabricated"from a stainless steel sheet having screen covered holes arranged in size and location to match the ports in the valve assembly housing. The screen provides support for the filters as in a standard hi vol. Flanges are formed on the four edges of the rectangular pan to add stiffness to the pan, provide guiding surfaces as the filter slides, and provide space for the sealing cover to separate it from the adjacent slide when the assemblies are stacked in storage cassettes. Dimensions of the pan are $13^{\prime \prime}(33 \mathrm{~cm})$ wide by $16 \frac{1}{2} "(41.9 \mathrm{~cm})$ long by $\frac{1}{2} "(1.27 \mathrm{~cm})$ thick. A rubber sheet, bonded to the central area of the pan enclosing the ports, and having $2^{\prime \prime} \times 2^{\prime \prime}(5 \times 5 \mathrm{~cm})$ openings over the eight directional ports, acts to locate the directional filters (Whatman-41) and provide an air leakage seal between all adjacent ports. The rubber sheet also has a center hole corresponding to the TSP port and provides a sealing area for the glass fiber center filter. Directional filters (Whatman-41) are individually mounted in $2 " \times 2 "(5 \times 5 \mathrm{~cm})$ plastic photographic film mounts prior to placement in the pan. Use of the $2^{\prime \prime} \times 2$ " mount provides a way to label the filter and handle it with minimum chance for damage or contamination through all steps including automated $x$-ray fluorescence analysis. After all filters have been installed in the pan, the sealing cover, with matching ports, is installed to clamp the filters in place through compression of an overlapping closed cell neoprene rubber seal. Two identical filter slide cassettes, having a capacity for 12 slides and two blank cover slides, are used with Air Scout. One cassette filled with unexposed slides acts as a slide supply cassette. The second (empty) cassette is placed in the exposed slide storage section and receives exposed filter slides as they move through the machine. The cassettes have a slot in one side which allows the bottom slide to be pushed out of the cassette by a transfer mechanism which moves it to a position over the hi vol sampling section. A closed cell foam neoprene sheet, with holes matching the sampling ports, provides an air leakage seal between the filter slide and the sampling ports. Suction from the hi vol also tends to improve the seal between the 
slide and the neoprene sheet. The transfer mechanism operates electrically on command from the slide sampling timer which can be preset for sampling times of 1 to 30 hours. When the timer actuates the transfer mechanism again, the new slide pushes the exposed slide to the storage section where it drops horizontally into the empty cassette. Th1s process continues on command of the timer until all 12 filter slides have been exposed and covered by one of the blank slides for protection.

A wind speed sensor, wind direction sensor, portable tower, recorder, and connecting cables make up the wind sensing system. A commercial 3-cup sensor having a small DC generator to provide electrical output is used for wind speed. Wind direction is sensed by a special sensor designed for use with the Air Scout. It operates through a rotating cam connected to the vane and having a face width equal to approximately a $45^{\circ}$ arc. The cam sequentially closes the contacts of 8 miniature enclosed commercial switches as it rotates. Each switch represents one of the 8 directions of the compass required and is aligned accordingly with the housing of the sensor and tower. In operation, when the contacts of one of the switches are closed by the cam, a circuit is completed, which immediately actuates the assigned solenoid and valve in the hi vol sampling section. The portable tower is assembled in sections. It is selfstanding, and may be erected on any relatively flat surface. (See Figure 4.)

A unfitized aluminum sheet construction was selected for the chassis to minimize weight. While adequate for most sites, this approach may be difficult to install in urban sites, such as flat roof tops with limited access stairways and doors. Figure 2. shows conceptual1y how the A1r Scout chassis could be redesigned as three separate modules which could be individually taken to a limited access site and assembled there. Alignment pins and overcenter latches could control the position of the modules with respect to each other on assemb1y. Wheels for ground. movement could also be removeable and optional. Functionally, no change in the operation of the Air Scout would be necessary; however, the total weight of the chassis would increase.

\section{Air Scout Operation}

Prior to taking the Air Scout to a fleld site, up to 12 filter slides are assembled by installing and labeling whatman-4l and glass fiber filters in filter slides as discussed earlier. The slide assemblies are then stacked in one slide cassette, covered by two blank slides, and the cassette installed in. the slide supply section of the Air Scout. A second empty cassette is installed in the exposed slide storage section. Calibrations of all recorders, sensors, and the hi vol are also checked. At the field site, installation of the Air Scout involves erecting the self-standing wind sensor tower and sensors, connecting cables from these sensors to the Air Scout, and connecting the Air Scout to a power outlet.

The desired slide sampling time is selected ( 1 to 30 hours). Operation mode (continuous or intermittent) is also selected. After confirming that the equipment is functioning normally, the hi vol and recorders are started and the first filter slide is moved into sampling position by using the manual control mode. The control mode is then switched to automatic and the equipment may be left to complete the sampling automatically. Once the equipment is installed at a field site, sampling can be continued with a minimum of servicing by sim- 
ply bringing to the site a previously assembled cassette of new filter slides to install in the slide supply section. The empty slide supply cassette is then transferred to the slide storage area, and the cassette of exposed slides returned for analysis. This completes the field slide servicing process. other periodic fleld servicing activities involve replacing the recorder charts for wind speed, direction, and hi vol air flow rate and checking calibrations.

The characteristics of a proposed site will have to be studied carefully prior to installing the Air Scout in order to achieve the best results. Aspects such as expected meteorology, possibilities of equipment vandalism, topography, general level of air contamination, relation of the source of interest to other sources nearby in terms of: compass location, similarity of pollution producing processes, and time related nature of the processes all must be assessed. These and other factors peculiar to each site as well as the purpose of the sampling w111 influence the slide sampling time and operating modes chosen.

\section{Testing}

The Air Scout is being tested in two phases. Phase I is a functional performance and reliability evaluation of the unit. Phase II is a field perform-. ance evaluation of Air Scout as part of a source identification system. During Phase II the limits of performance with respect to multiple source resolution as well as the influence of sampling times and flow rates will be explored.

In Phase I, the functional performance and reliability evaluation involved examining each of the major components and subsystems of the Air Scout. These consisted of the windvane, slide changing mechanism, valves, solenoids and timers. The windvane described above was exposed to the elements, including early winter, for 3 months with no evidence of malfunction or signs of corrosion. The slide changing mechanism was continuously cycled approximately 9 times per minute for over 500 hours to check life. No failures occurred. In normal use the changing mecharism will be activated only once per slide change based on the time interval selected for filter exposure ( 1 to 30 hours). The poppet valves described above were cycled with both push- and pull-type solenoids. One push-type solenoid was operated to destruction, 200,000 cycles, which was considered to be within statistical limits of its normal life. Testing is continuing using a push-type solenoid with a design life of $1,000,000$ cycles. It has passed 300,000 cycles. No leakage has occurred across the valve seat. The commercial cycling timer selected for the slide changing mechanism is being used for these tests. It has been time-tested through use with several valve design variations to over 600,000 cycles.

Phase II field testing has just been started to determine the validity of data from the Alr Scout. Tests will be conducted in various environments (clean site, dirty site, single known contaminant source, and multiple known contaminants) for the purpose of comparing the amount and type of particulate matter between the Air Scout and a standard high volume air sampler. For testIng in a clean site, the Air Scout has been placed in a relatively clean roof top environment which is best described as non-industrial suburban. Four standard high volume air samplers and the Air Scout are positioned near the western edge of the roof about 20 feet $(6 \mathrm{~m})$ above ground. All units are arranged to sample from the same mass of air in the prevailing wind. One pair of hi vols is equipped with glass fiber filters and the other pair with Whatman-41 filters. 
Alr Scout is equipped with a glass fiber over the center opening and Whatman41 in the directional positions. Tests will be conducted at constant air flow rates of 50,40 and $30 \mathrm{cfm}\left(0.025,0.020\right.$ and $\left.0.015 \mathrm{~m}^{3} / \mathrm{sec}\right)$ relative to the $8 \times 10$ inch $(21 \times 26 \mathrm{~cm})$ high volume air samplers. Filters will be changed at intervals of 4,8 and 12 hours. Exposure time and flow rates will be varied to determine the minimum conditions necessary to collect an air sample yielding meaningful results upon analysis. Tests at a dirty site will be carried out in a highly industrialized location in the Cuyahoga River Valley. Setup and operation will be the same as the clean site. Comparison of operating time with the clean site will be of prime interest. The third segment of the field tests involves going to a known isolated source of contamination. Each of two $3 / 4$ ton open trucks have been equipped with a pair of standard high volume air samplers and a motor generator set for power. Each is a selfcontafned mobile unit capable of being driven to any convenient site. One pair of hi vols will be positioned up wind of the source to monitor incoming air. The other pair of hi vols and the Air Scout are positioned down wind of the source being studied. These tests must be conducted when stable meteorological conditions are predicted for the test time or results would not be valid. Analysis of the samples determine what has been added by the source. Final field tests will be conducted at a site having several known individual contaminants and will be similarly monitored as a final field test to determine Air Scout's tracking and identifying capability in multiple source resoIution.

\section{Conclusion}

A portable wind sensitive directional particulate air sampler has been designed and fabricated. Functional testing of its components and subsystems has been completed with all items exhibiting performance and life sufficient to carry out field performance tests. Critical to reliable operation are the wind direction sensor and the directional porting valves. Life testing of these two components has been particularly emphasized with successful results. Field testing has been initiated and will concentrate on evaluating the Air Scout as a source identification too1. Initial tests will evaluate its performance compared to standard hi vols in both clean and dirty atmospheric environments. Its directional resolving capability will then be assessed first with an isolated source and finally with multiple sources. The Air Scout concept appears to offer significant advantages as a source identification tool. Completion of the test program now underway will permit further assessment of Its potential based on use under actual field conditions. 


\section{References}

1. R. B. King, J. S. Fordyce, A. C. Antolne, H. F. Leibeck1, H. E. Neustadter, S. M. Sidik, J. C. Burr, G. T. Craig, C. L. Cornett, "Preliminary analysis of an extensive one year survey of trace elements and compounds in the suspended particulate matter in Cleveland, Ohio," presented at Earth Environmental Resources Conference, Philadelphia, Pa., September 10-12, 1974, NASA TM X-71586.

2. Climatological Data for Cleveland, Ohio: National Weather Service NOAA, Ashville, N. C.

3. H. E. Neustadter, R. B. King, J. S. Fordyce, "Elemental composition of suspended particulates as functions of space and time in Cleveland, Ohio," to be presented at 68th Annual Meeting of APCA, Boston, Mass., June 1975, NASA TM X-71688.

4. D. L. Duewer and B. R. Kowalski, "Forensic data analysis by pattern recognition categorization of white bond papers by elemental composition," Analytical Chemistry, vo1. 47, no. 3, March 1975.

5. K. A. Rahn, G. Beke, G. Windels, "An automatic filter changer for collection of short-period high volume aerosol samples," Atmos. Envir. ㅇ, 635643 (1974).

6. T. A. Cahil1, R. G. Flocchini, "Regional monitoring of smog aerosols," Annual Report to the California Air Resources Board, Crocker Nuclear Laboratory, University of California, Davis, Calif., Report UCD-CNL 184, November 1,1974 .

7. R. A. Duce, G. L. Hoffman, W. H. Zoller, "Atmospheric trace metals at remote northern and southern hemisphere sites: Pollution or natural?", Science 187, 59-61 (1975). 


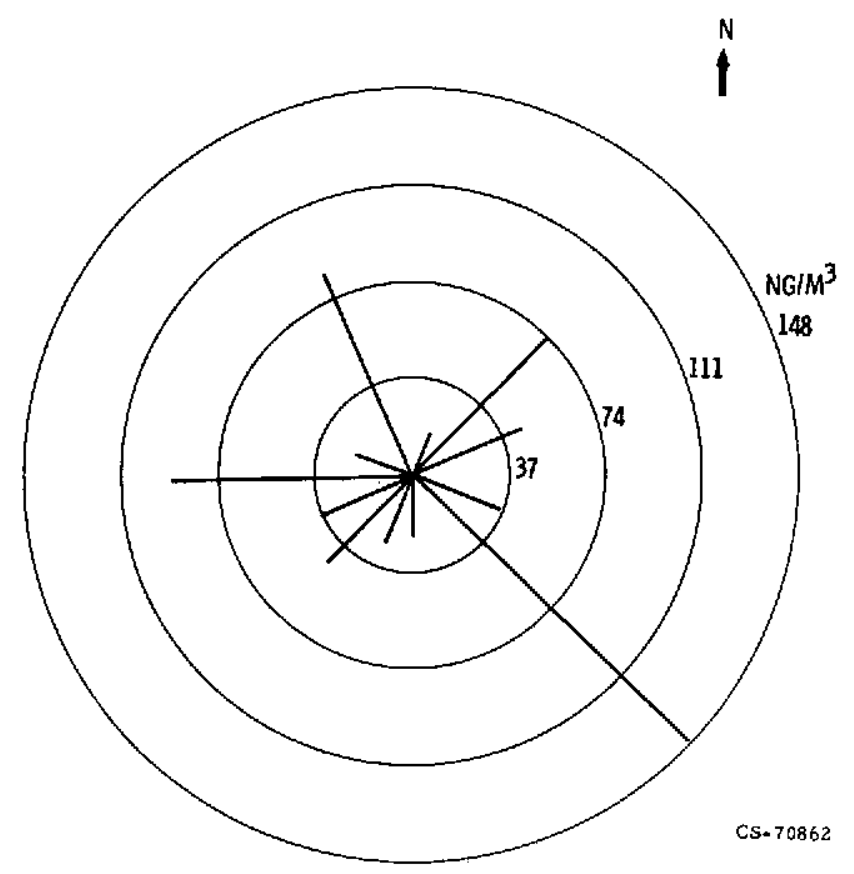

Figure 1. - Typical monltoring site concentration rose.
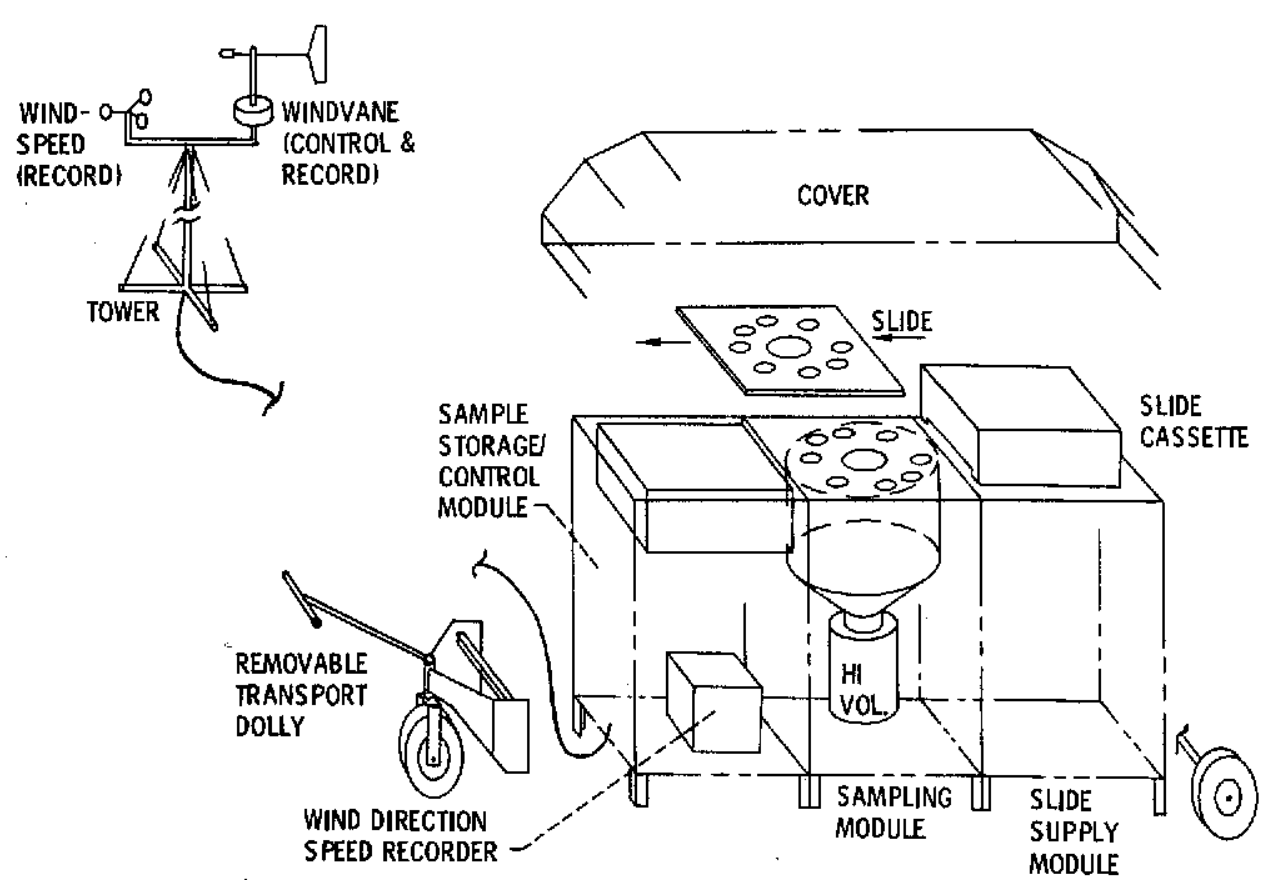

Flgure 2. - Air Scout arrangement and modular chassis concept. 


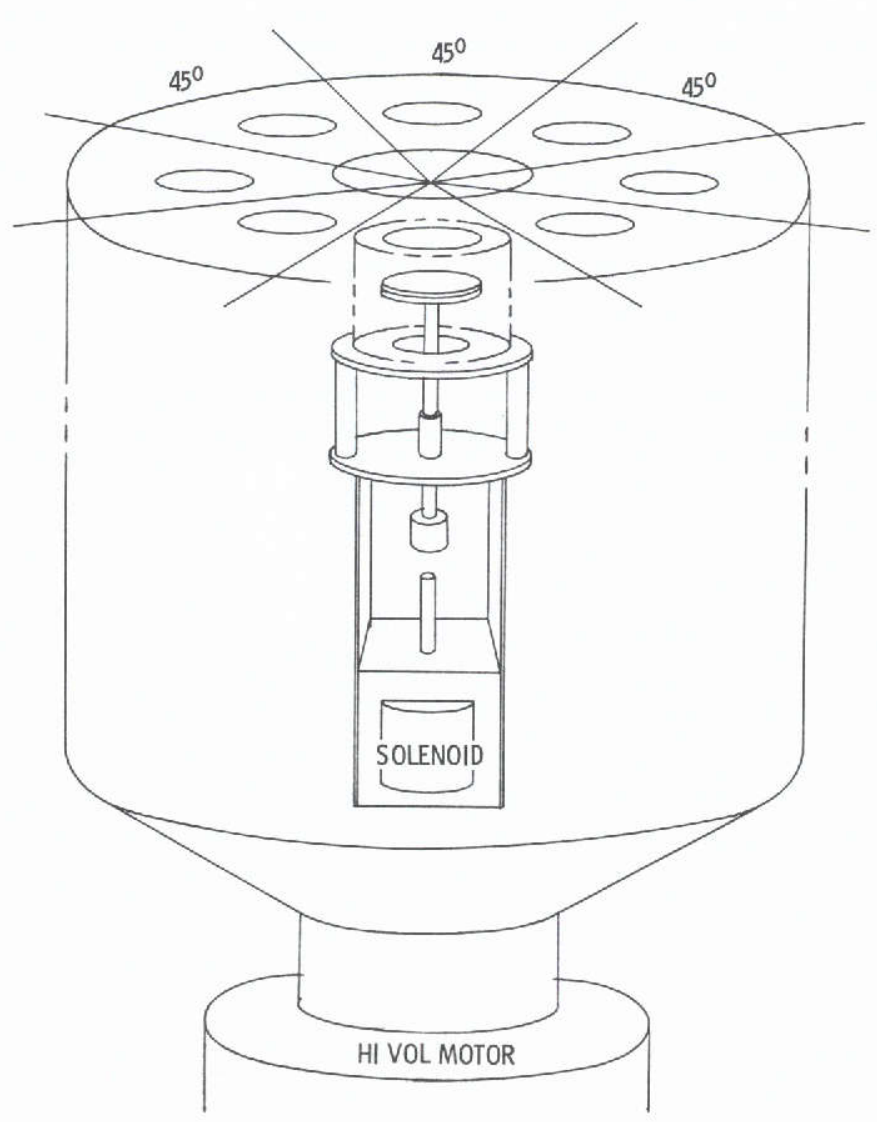

Figure 3. - Directional porting and valve arrangement

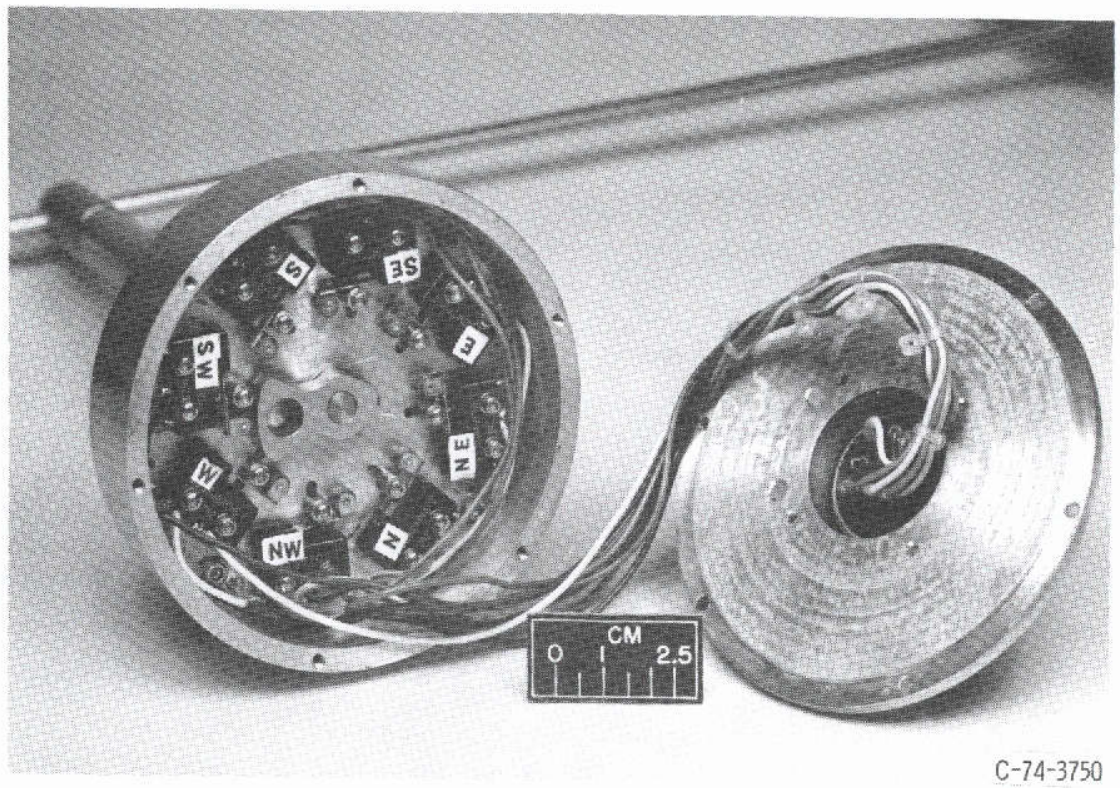

Figure 4. - Wind direction sensor. 